\title{
THE TRAINING AND USE OF RESEARCH ASSISTANTS FOR A SURVEY IN A THIRD WORLD SETTING
}

\section{Eugenie Frances Hildebrandt}

Any activities designed to promote bealth and prevent disease should stem from a data base. In community nursing that data base is frequently obtained by way of a survey. A survey often plays a vital role in giving direction to action.

Survey research is vulnerable due to the difficulty in controlling the experiment when a living, moving, thinking community is the test tube. This vulnerability can be greatly reduced with adequate investment of time, supervision and field worker training.

This article will offer an approach to data collection in a third world setting by indigenous workers using methods that maximize the accuracy and quality of the data collected.

\section{Purpose and setting}

The purpose of the survey was to collect baseline data about 1) the family and community support systems, 2) the heal th status and 3) perceived needs of persons of at least 60 years of age in a black township with a population of approximately 100,000 . The data collection was the preliminary step in the development of a planning model for community health and supportive services that facilitate self care.

\section{Survey Tool}

The questionnaire was translated into the two black languages that dominate the township in which the survey was done. The researcher felt it better to have one interpretation of a word or phrase that everyone would use rather than have each of 15 field workers use his or her own interpretation from English to the language of the home in which they were interviewing. This objective was accomplished but the English version of the questionnaire proved to be more popular with the field workers once they had studied the Zulu and Sotho versions. Perhaps this was because their advanced education was done in the official languages of the country.

The tool used a combination of open and closed questions. The questions asking for the respondent's opinion or feelings about a situation made strong demands on the field workers ability to handle languages.

\section{ABSTRACT \\ This article describes an approach to gathering data in a black township. It emphasizes the importance of using in. digenous interviewers and offers sugges- tions for their training. Innovative techniques were used to help the field workers to understand and apply the concept of randomization to the streets and houses of their Township. It em- phasizes the need to supervise and rein- force the research standards throughout the data collection process. \\ UITTREKSEL \\ Hierdie artikel beskryf ' $n$ benadering tor die insanel van gegewens in ' $n$ Swart woonbuun. Klem word gele op die be- langrikheid van die gebruik van Swart onderhoudvoerders, en maak voorstelle vir hulle opleiding. Kreatiewe tegrieke is gebruik om begrip by die veldwerkers te fasiliteer, asook die konsep wan ewe- kansigheid ten opsigte van die strate en huise van die woonbuurt. Nadruk is gele op die behoefie aan supervisie en bege- leiding, en op die navorsingstandaarde in die proses van insameling van gege- wens.}

\section{Recruitment of workers}

Interviewers were paid for each questionnaire that was completed correctly. Fowler (1988) states that the use of volunteer interviewers is almost always unsuccessful. It is difficult to require volunteers to attend training sessions, attrition is often high and response rates are often low because poor interviewers are not excluded.

Demographic profiles of the interviewers are generally not addressed in detail in survey research reports. Yet Babbie, as early as 1973, pointed out the importance of the acceptance of the interviewer to the person being interviewed. The researcher believes that this issue is much more significant in a third world setting. People here often have not traveled or interacted with people different from themselves in colour, culture and outlook. As a result, they do not have a broad range of people with whom they are comfortable. Prinsloo et al. (1989) speaks of the negative effects of fieldworkers from outside the cultural setting of her study population. Padayachee (1989) used interviewers from the same township as the study population and reported no difficulty.

Residents of the township were recruited to do the survey. It was felt that 1) people will be less suspicious and more likely to participate if asked to do so by someone they know or at least know comes from within their community and 2) people communicate more readily and freely with someone of their own ethnic background. The use of indigenous workers helps to resolve the barriers of distrust, race and language. An additional potential bias may still occur among people historically from different black nations.

This use of indigenous field workers resulted in a very low refusal rate among the persons who were approached by the field workers. Most field workers reported no refusals and no one had difficulty finding willing participants. By comparison, in one stage of a study done in the northern suburbs of Cape Town (Wicht et al 1989) a 51\% failure rate was experienced because respondents were distrustful and reluctant to provide information and the field workers felt threatened. A subsequent stage of that study used people who were familiar with the area and moved about in it freely and apparently better results were obtained.

It was imperative to successful interviewing that the field workers have interpersonal, communication and literacy skills. Initially, retired nurses and teachers were sought but this pool of people proved to be too small and the criteria shifted to include working teachers and nurses and well screened people who had matriculated. Recruitment was done by word of mouth through the nursing clinic, school staff, the township social workers and an older adult recreation group. These people filled out basic applications and their references were checked prior to their job interview. 
Since the majority of the applicants and their references did not have telephones, this was time consuming and often involved sending messages via another person. The township communication system is good though it often starts and ends with someone saying "we will send a child to tell them".

\section{Training of Field Workers}

It is imperative to train workers. The key goal of the training must be to develop a mutual understanding and "ownership" of the effort. This can only be accomplished if the researcher abandons the authoritative role of the lecturer. The trainer must instead create an excitement among the field workers about what this project will do for their community and a pride for their contribution to this effort. At most, the researcher can be the "first among equals". One must never take for granted the value to the project of the field workers' intimate knowledge of the community and the culture. These make as vital a contribution to the success of the data collection as does the researcher's knowledge of survey structuring and data analysis. It is truly a dependent relationship and a good survey can be obtained only when both parties know this and respect it.

The other goal for the training is to have the field worker reach an understanding of how the survey must be conducted: how to assure a representative sample and how to ask questions and record information. A simple training manual is very helpful here. It should contain the important points made during the training sessions so the field workers can review and refer back to the information. It should include the purpose of the study and the use that will be made of the information. An information sheet that will be shared with each potential interviewee can also be included here. Practicing with the survey tool is necessary. It is helpful to start the practice sessions by role playing an interview. Most of the field workers recruited for this study were not practiced in filling out questionnaires and were working in their second language so they needed practice with the questionnaire and practice with a variety of partners.

The researcher may find the progress of a few of the trainees is slow so that they are not skilled enough by the end of the sessions. These people can be diplomatically encouraged to drop out if they find it too difficult. Often people only need permission to admit this to themselves. Alternatively, the researcher may tell them to practice on family or friends and return when they are confident they can manage the work. Only the highly motivated do this and these often turn out to be excellent workers.

Two days of training is considered minimal (Fowler, 1988).
This researcher found it worked well to do two sessions with the entire group and another session of one to two hours with each field worker after the first questionnaire was completed. Subsequent individual sessions, after every five questionnaires were completed, were used to reinforce information and the responsibility to quality.

\section{Pilot Study}

A pilot study was done and proved to be very valuable in wording the questions more understandably in the township setting. The experience with the pilot and actual data collection lead to a recommendation that the pilot be taken through the entire coding procedure before the final form of the questionnaire is determined.

\section{Survey Procedures}

The survey sample was obtained by stratified cluster sampling. Three hundred persons 60 years of age or older were interviewed.

Township maps were obtained from the township planner which identified each stand by number. A factor that greatly enhanced the accuracy of this approach was that the administration had plotted six new extensions to the township and had recently moved all previous squatters onto these stands. Therefore, even though these occupants had informal houses, they were situated on a plotted stand identified on a map. Backyard squatters in the older parts of the township were interviewed as separate households. Many of these had also been relocated to the newly plotted stands by the time the survey was done.

Field workers were assigned a "cluster" of approximately $\mathbf{5 0}$ stands from which they were to interview 5 people. They started at a stand randomly chosen by the researcher. A brightly coloured marker was used to draw around the parameter of each cluster. This map was posted on a wall so field workers could identify their cluster, its relationship to landmarks and to the rest of the township. The researcher had the map duplicated so this second map could be cut up into the individual clusters. The field workers were given these "mini maps" with the stand numbers and street names, which they found invaluable for reference when they actually went into the area in which they were to collect data. In addition to the piece of the total map, the field worker was given five questionnaires to be completed in that cluster. When finished, these were brought to the researcher at a prearranged location in the township. Schools or the township library building were excellent places to meet field workers because they were politically neutral. The researcher and the field worker reviewed the questionnaires together. Any clarification of the responses could be done at that time. Also, if questions had been forgotten or other errors made, the field worker could immediately go back to the household to finish or correct the question- naire. Any re-teaching or reinforcement necessary could be done at that time also. This was a lengthy process with the early interviews. It became much shorter as the workers gained skill and familiarity with the tool and the interview process. It was an excellent quality control because field workers knew they would, in person, be held responsible to the researcher for each page of each questionnaire. Errors did occur. One individual did not take seriously the need to start at the stand picked via the random number table. After the hot dusty walk to her cluster she started with the closest stand. The need to stay true to the study design was re-taught and reinforced when the questionnaire had to be rejected and of course the worker could not be paid for it.

Much positive reinforcement is advised during the actual data collection phase. This was done verbally at each meeting with the field workers, every time after five questionnaires had been completed. Positive comments were also written on the questionnaire at that time. Payment was offered immediately at the time each cluster was completed and the five questionnaires were reviewed and acopted by the researcher. This necessitated carrying cash into the township each day, but it was a powerful incentive. Some workers preferred to wait for payment until the end of the task, and some accepted cheques, but all of them were given a choice of time and method of payment.

\section{Validation}

The actual work of the field workers must be checked to support the validity of the data collection. A real concern about survey field workers is that they will complete the questionnaires at their own kitchen table. "In the long run, probably the best protection against 'faked' interviews is to have a set of interviewers that has some commitment to the quality of the research and the organization" (Fowler 1988, 122).

Four per cent of the interviews were checked. The work of each interviewer was checked in one of two ways. A worker was asked to repeat a questionnaire after it had been done by another worker. These two were then compared by the researcher. Alternatively, homes were visited by the researcher and the field worker who had done questionnaires at these particular homes. These were "friendly visits" done in part to express a thank you for their participation and it was quite simple to determine in the course of the conversation that 1) the worker had done an interview and 2) some facts such as the age, living situation and number of children of the respondent.

When a worker was asked to repeat a coworker's questionnaire it was a powerful reminder that her work, 100 , would be checked. One teacher expressed indignation that she was checked by a "non-professional person", 
but generally this step was accepted as necessary to the quality of the project and the interviewers also realized their payment was tied to it.

\section{CONCLUSION}

The use of indigenous field workers was seen as supporting more honest responses, resulted in a low refusal rate and helped to ready the community for programmes based on the findings of the survey. It does require careful explanations of 1) why and how the survey must be carried out in the way it is and 2) why and how questions must be asked in the way they are. Frequent communication between the researcher and field worker is also vital .

This survey was supported by a grant from the Human Sciences Research Council.

\section{REFERENCES}

BABBIE E.R. 1973. Survey Research Methods. Belmont, CA: Wasworth.

FOWLER F. 1988. Survey Research Methods. Newbury Park, CA: Sage.

MULLAN F. 1982. Community oriented primary health care. New England Journal of Medicine. Vol. 307, No. 17. 1076-78.

PADAYACHEE G.N. 1989. A communitybased study of the aged in Lenasia, Johannesburg in Ageing in South Africa. Ferreia M, L S Gillis and V Moller, Eds. Pretoria: Human Sciences Research Council.

PRINSLOO R., A. SKIBBE and C. J. LOMBARD. 1989. A comparison of the functional status of two elderly population groups (white and coloured) in the south-
Westem Cape in Ageing in South Africa.

Ferreia M., L.S. Gillis and V. Moller, Eds.

Pretoria: Human Science Research Council.

WICHT C.L., F.R. PRINSLOO, A SKIBBE, C.J. LOMBAARD and E.J. LOMBARD. 1989. An investigation into the heal th services for and related needs of the aged. Pretoria: Human Science Research Council.

Eugenie Frances Hildebrandh $R$ N.

Master of Science in Nursing University of Wisconsin--Madison

Madison, Wisconsin U.SA.

Registered Nurse

Nurse Practioner

University of the Witwatersrand Department of Nursing Education

PhD Candidate 